UCRL-ID-131673

$\vdots$

\title{
Aging Effects on Explosive Performance
}

\author{
Ben Wu \\ Clark Souers
}

August 20, 1998

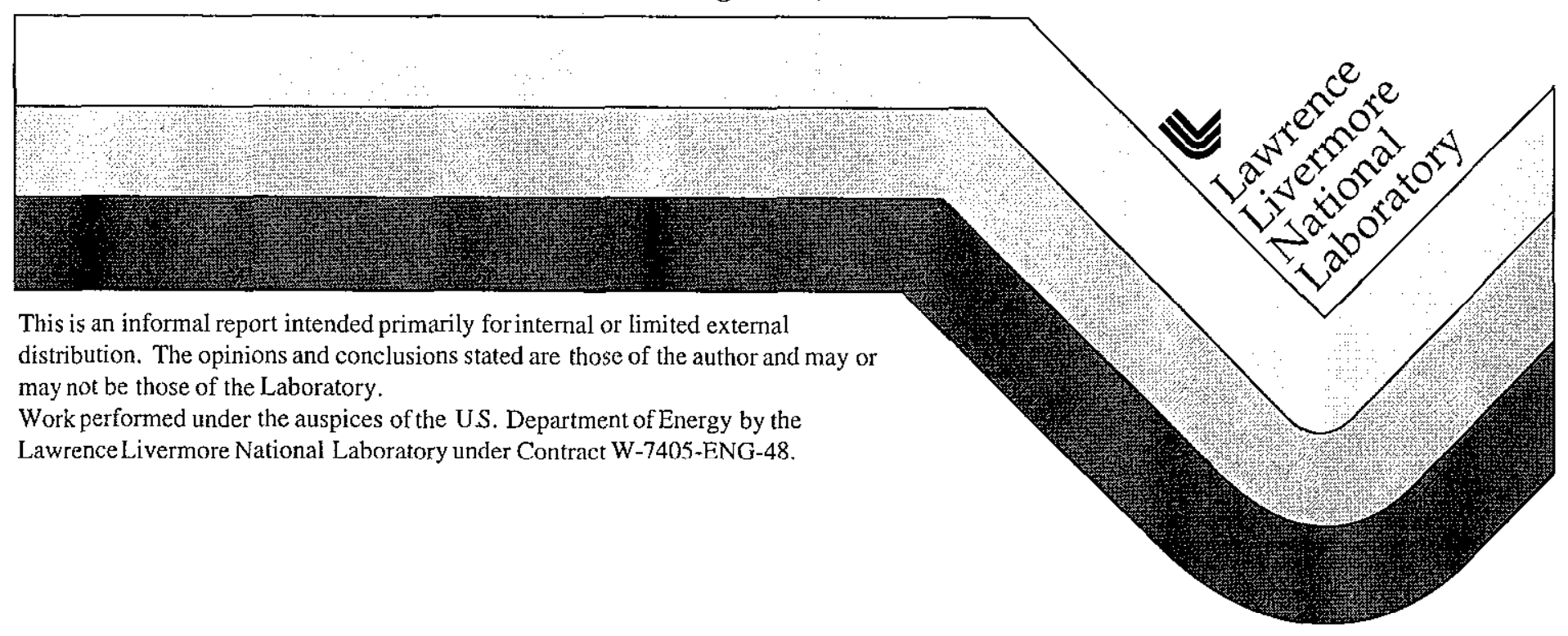




\section{DISCLAIMER}

This document was prepared as an account of work sponsored by an agency of the United States Government. Neither the United States Government nor the University of California nor any of their employees, makes any warranty, express or implied, or assumes any legal liability or responsibility for the accuracy, completeness, or usefulness of any information, apparatus, product, or process disclosed, or represents that its use would not infringe privately owned rights. Reference herein to any specific commercial product, process, or service by trade name, trademark, manufacturer, or otherwise, does not necessarily constitute or imply its endorsement, recommendation, or favoring by the United States Government or the University of California. The views and opinions of authors expressed herein do not necessarily state or reflect those of the United States Government or the University of California, and shall not be used for advertising or product endorsement purposes.

This report has been reproduced directly from the best available copy.

Available to DOE and DOE contractors from the Office of Scientific and Technical Information

P.O. Box 62, Oak Ridge, TN 37831

Prices available from (615) 576-8401, FTS 626-8401

Available to the public from the

National Technical Information Service

U.S. Department of Commerce

5285 Port Royal Rd.,

Springfield, VA 22161 


\title{
Aging Effects on Explosive Performance
}

Ben Wu and Clark Souers
August 20, 1998

TLL-16

\begin{abstract}
Bigplate and the Cylinder Test have been pushed into baseline LX-17 measurements. The non-ideality of LX-17 and the need for a time-dependent Equation of State has been shown. The first calculations of Equilibrium CHEETAH (TTL-06) linked to the 2-D code HEMP were made. An unexpected time lag not predicted by the code was seen in Bigplate. Extensive metal spall was also seen.
\end{abstract}

\section{Objectives}

The objective is to run new and aged stockpile explosives in Bigplate and the Cylinder test to see if the performance has degraded with time.

\section{Definitions}

Peformance refers to the pressure-energy-time output of an explosive that has been promptly detonated. ie. ignited with full input energy. The Equation of State is the specific equation, table or code that provides this information to the hydrocode that models the experiment. Ideality means how close the explosive is to the simple, instantaneous equation now used in the codes. The code used here was 2-D HEMP.

Bigplate consists of a disk of pressed explosive of $100 \mathrm{~mm}$ radius and a 20 to $40 \mathrm{~mm}$ thickness with a $0.5 \mathrm{~mm}$ thick copper or tantalum plate glued to the front. A point detonator on axis at the back creates a spherical shock wave that interacts with the copper at $0^{\circ}$ on-axis out to $76^{\circ}$ at the edge. Five Fabry laser beams measure the velocity on the front edge of the copper at the $0,10,20,40$ and $80 \mathrm{~mm}$ positions.

The Cylinder test consists of twelve stacked parts with a radius of $12.7 \mathrm{~mm}$ and an overall length of $300 \mathrm{~mm}$. Pin rings on the sides measure the detonation velocity, and a streak camera measures the detonation front curvature on the end as the detonation breaks out. The curvature is an excellent test for non-ideality.

\section{Milestones}

Three LX-17 baseline shots with fresh explosive were fired this year. Two complete sets of machined cylinder parts of aged LX-17 were obtained from Pantex. 


\section{Deliverables}

Ten data files per shot, which may be used by an investigator who wishes to model Bigplate. Bigplate offers an unusual test for an explosive Equation of State in that the detonation crosses most.zones obliquely. Once obtained, these files constitute a standard for the future.

A full analysis of all the data of the past years was made, with an extensive sensitivity study. This brought forth the unexpected time lag seen in all three explosives. Also unappreciated previously was the extreme degree of metal spall on the copper plates, seen with all three explosives.

Baseline LX-17 shots that make up the fresh part of the LX-17 study. Aged and accelerated aged LX-17 samples should be fired for comparison.

The LX-17 was fired with ultrafine TATB boosters, whose ideality lies between that of LX-04 and LX17. For the first time, the TATB booster was modeled into the code.

\section{Accomplishments}

State-of-the-art Fabry-Perot velocimetry was used for the Bigplate shots, and the unparralled accuracy achieved with five simultaneous laser beams is itself an accomplishment. The copper velocity was measured to $\pm 0.066 \mathrm{~mm} / \mu$ s or $1 \%$. The jump-offs (leap-up at the start of the copper velocity) were seen to $\pm 0.01 \mu \mathrm{s}$ (the smallest number ever) and the first plateau lengths measured to $\pm 0.02-0.04 \mu \mathrm{s}$. Short (1-2 $\mu \mathrm{s})$ and long $(10 \mu \mathrm{s})$ Fabry runs overlapped to $\pm 0.05 \mu \mathrm{s}$. Thus, ten curves were taken per shot, an extraordinary amount of data.

A total of $2 \mathrm{LX}-14,5 \mathrm{LX}-04$ and $3 \mathrm{LX}-14$ shots have been made. These explosives are, in order, very non-ideal, somewhat non-ideal and almost ideal so that a spectrum of behavior has been studied with the same tests. The non-ideal LX-17 did not produce good code results when run with the usual Equation of State equation. The use of static tables also did not work. We conclude that a time-dependent Equation of State (ie. with kinetics) is needed for a good description. Figure 1 shows the inadequate results of running Bigplate with linked Equilibrium CHEETAH (Larry Fried, TTL-06). CHEETAH is a thermochemical code with a large thermodynamic library. What is missing is time, which will be supplied by the new experimental code KINETIC CHEETAH.

A four- chapter detailed account of the Bigplate shots has been written and will be published in September of this year. It is: P. Clark Souers, Steve Anderson, Rex Avara, Larry Fried, Jim Janzen, Stella 
McGuire and Ben Wu, Bigplate: An Oblique Angle Explosive EOS Test (U), text:U, Lawrence Livermore National Laboratory, URCL-ID-131282, to be published, September, 1998.

The most unusual Bigplate find was that 7 of 9 shots showed a unexplained $0.1 \mu$ s lag between the jump-off at $0 \mathrm{~mm}$ and at $80 \mathrm{~mm}$. An example is shown in Figure 2. One hypothesis is that the detonation wave is slowed down by friction along the inner face of the plate. The current production code does not predict this effect.

All samples showed unexpectedly large metal spall, which extended the on-axis first plateau time by $0.1 \mu$ s and created a "rebound" bump on the second plateau as seen in Figure 3. The spall diminished to near-zero at the plate edge. The spall was larger than that seen in 1-D shots, probably because of the cumulative push of the front sideways across the plate. This required time-zero resets of the curves for explosive Equation-of-State analysis. This has also encouraged the push to create an improved metal spall model in the production code.

\section{Figure Captions}

Figure 1. Comparison of the on-axis data and Equilibrium CHEETAH code run for non-ideal LX-17. Although CHEETAH (TTL-06) has far more thermodynamic information that any other Equation of State, the absence of time in it makes for poor results. KINETIC CHEETAH, under development, should fix this problem.

Figure 2. The unexpected time lag seen here in LX-04. The on-axis $0 \mathrm{~mm}$ measured data and code are locked together in time, with the $80 \mathrm{~mm}$ edge results being locked in time as well. The actual experiment starts $0.1 \mu$ s later than predicted by the code. This effect was seen for all three explosives and its cause is unknown.

Figure 3. Metal spall seen in LX-04 and compared with a nearly spalless code run. The first velocity plateau is extended by the spall and a hump appears on the second plateau. Spall has an effect on the overall timing of the explosive. 


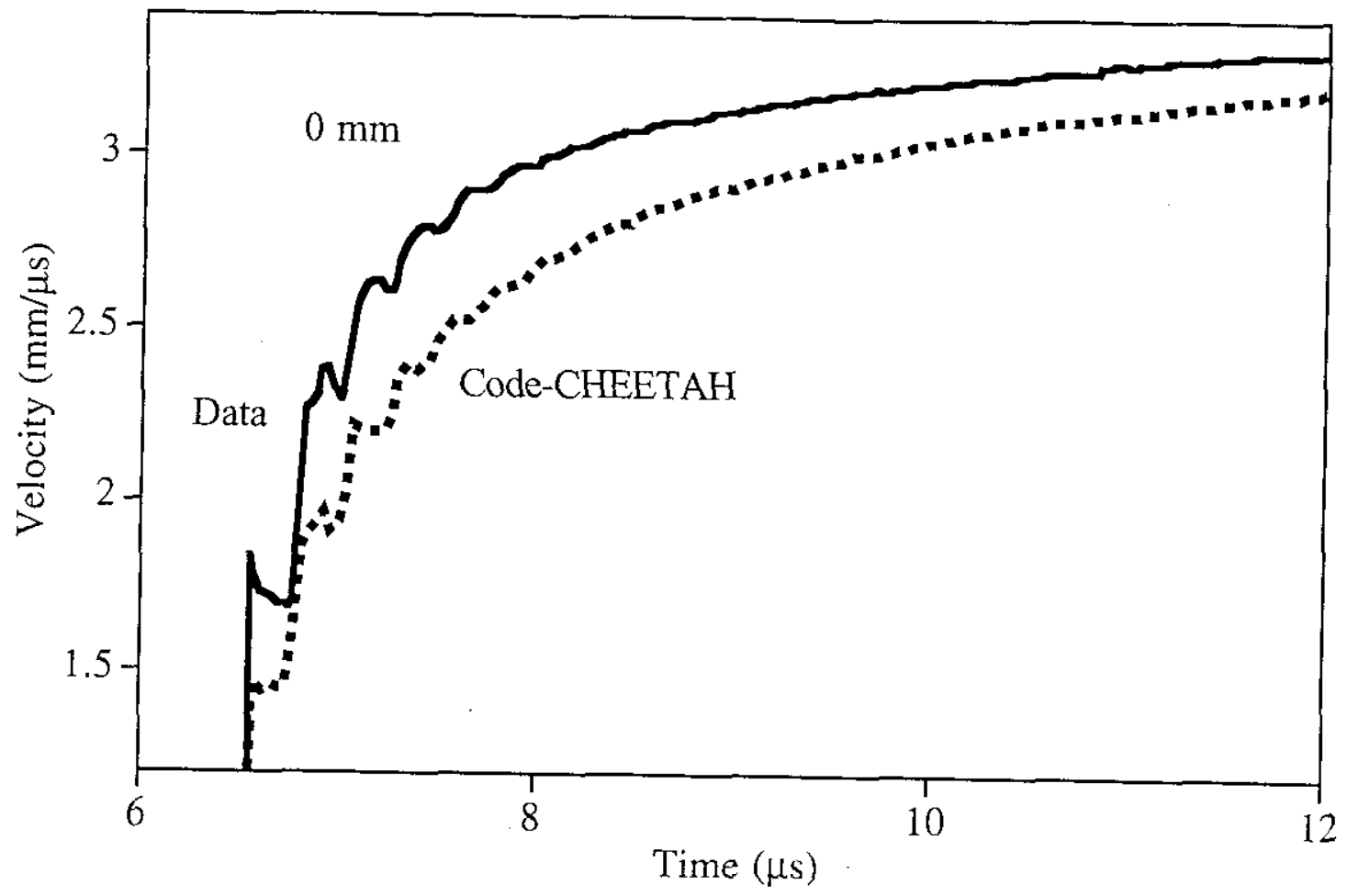

Figure 1 


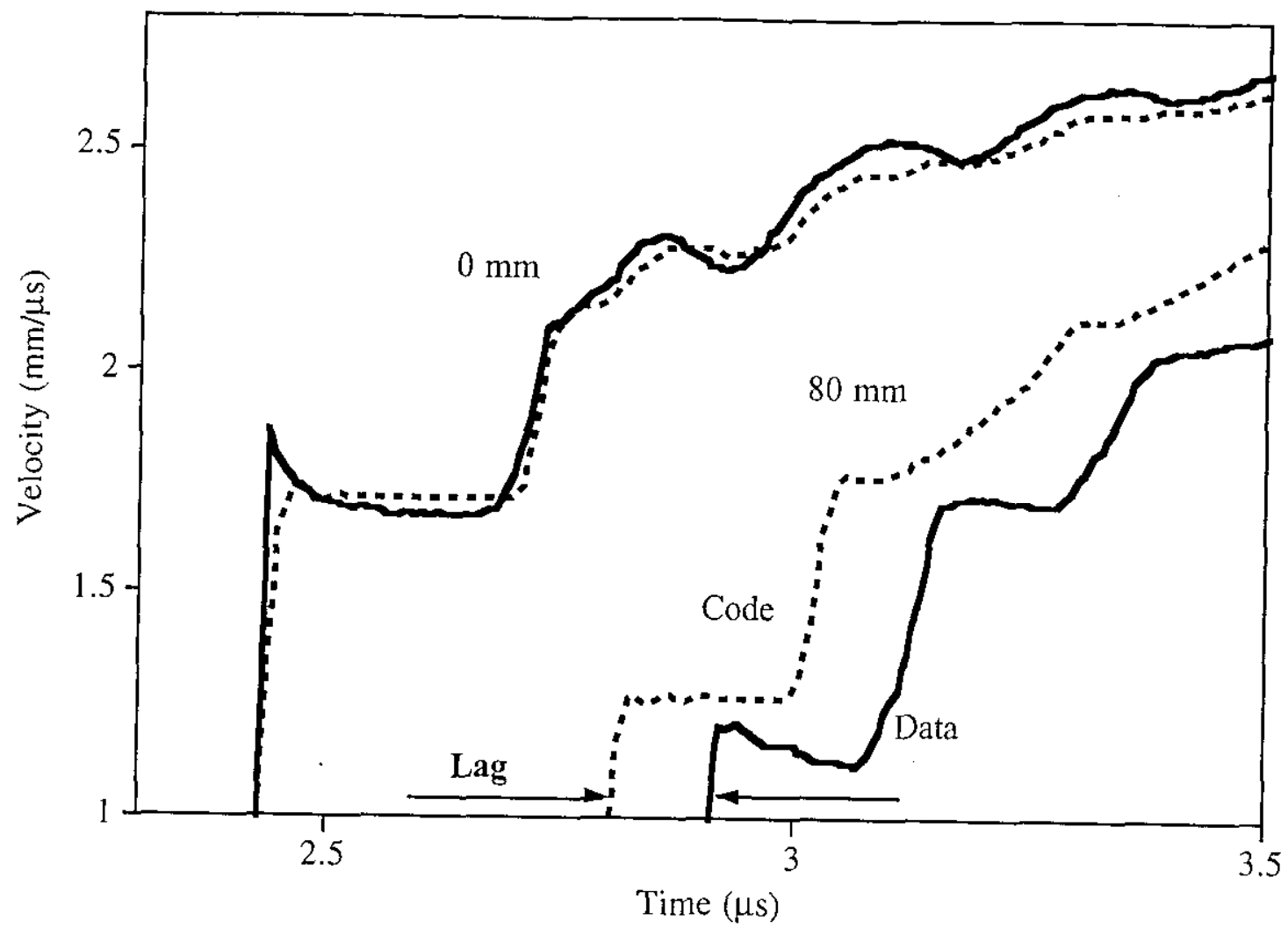

Figure 2 


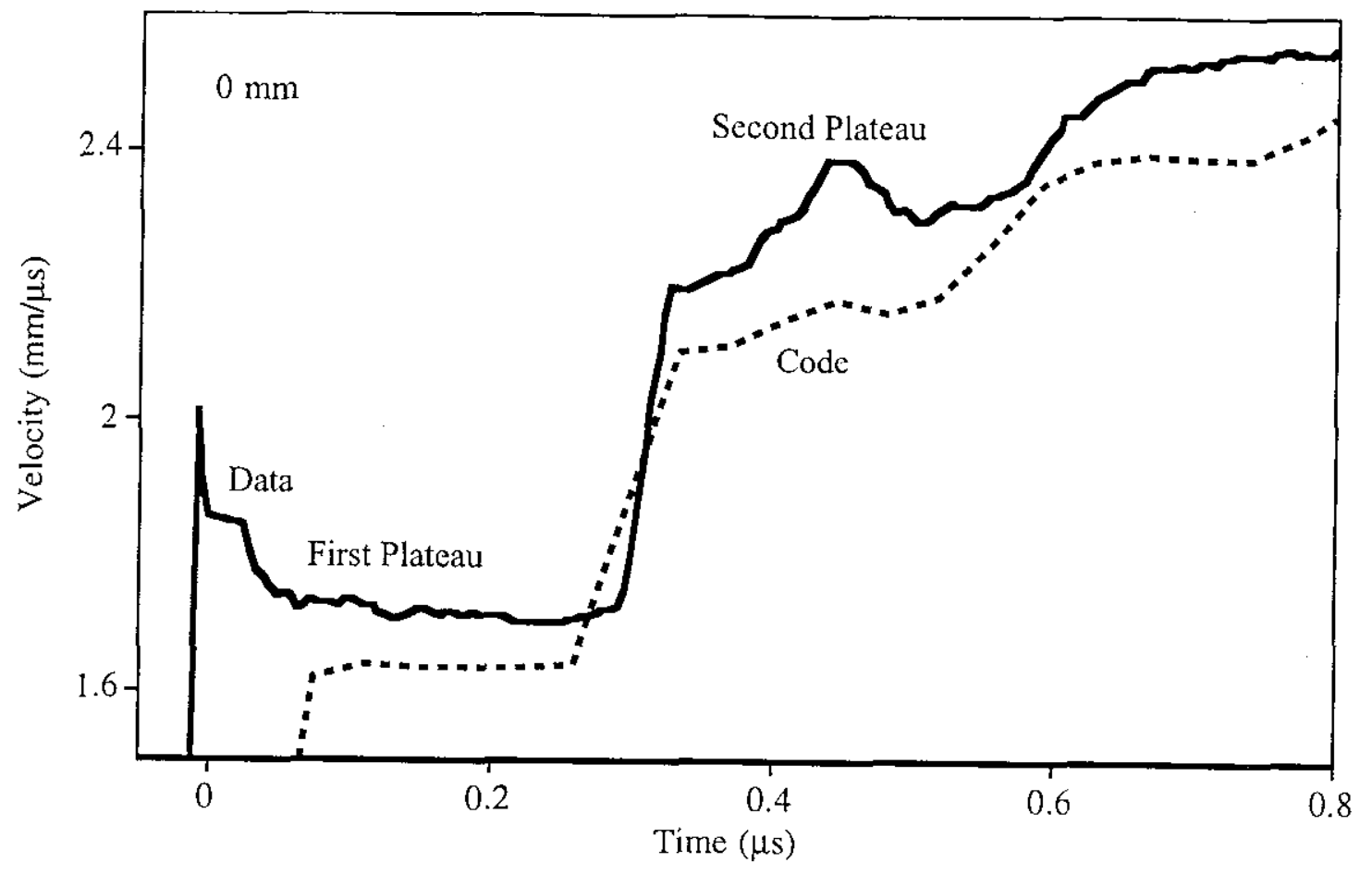

Figure 3 